Check for updates

Cite this: RSC Adv., 2018, 8, 9802

Received 12th December 2017 Accepted 26th February 2018

DOI: $10.1039 / c 7 r a 13264 f$

rsc.li/rsc-advances

\section{Synthesis of a surface molecular imprinting polymer based on silica and its application in the identification of nitrocellulose}

\begin{abstract}
Yan Yang, Xiangjun Meng and Zhenggang Xiao (iD *
A surface molecular imprinting polymer (MIP) based on silica ( $\left.\mathrm{SiO}_{2} / \mathrm{MIP}\right)$ with excellent selective identification properties towards nitrocellulose (NC) was synthesized with methylacrylic acid as a functional monomer and NC as a template molecule, through simple in situ polymerization. The functional groups of $\mathrm{SiO}_{2} / \mathrm{MIP}$ were studied through Fourier transform infrared spectroscopy. The morphology, crystalline state and thermostability of $\mathrm{SiO}_{2} / \mathrm{MIP}$ were investigated respectively by scanning electron microscopy, X-ray diffraction and thermogravimetric analysis. Binding capacity and selectivity studies of $\mathrm{SiO}_{2} / \mathrm{MIP}$ for $\mathrm{NC}$ and its analogues were carried out through ultraviolet-visible spectrophotometry. The thermal analysis and study of crystalline states confirmed the successful imprinting of $\mathrm{NC}$ in the polymer networks. The optimized conditions were found to be a polymerization temperature of $45{ }^{\circ} \mathrm{C}$ and a functional monomer to cross-linking ratio of $1: 3$. The adsorption capacity of $\mathrm{SiO}_{2} /$ MIP was improved considerably compared with that of polymers prepared by traditional imprinting technology, with a maximum adsorption amount of $1.7 \mathrm{mg} \mathrm{mg}^{-1}$ in $2 \mathrm{mg} \mathrm{ml}^{-1} \mathrm{NC}$ solution, compared with an adsorption capacity of about $0.5 \mathrm{mg} \mathrm{mg}^{-1}$ for a traditional MIP. According to the selectivity study, more $\mathrm{NC}$ was adsorbed by $\mathrm{SiO}_{2} / \mathrm{MIP}$ than its analogues; the best adsorption capacity of $\mathrm{SiO}_{2} /$ MIP for NC was approaching 5 times that for carboxymethyl cellulose (CMC). The results show that it would be possible to apply $\mathrm{SiO}_{2} /$ MIP for the detection of $\mathrm{NC}$, to give improved sensitivity in security checking and improved contaminant adsorption.
\end{abstract}

\section{Introduction}

Nitrocellulose (NC), a cellulose derivative, is a type of explosive material, which is the basic component of single and double base propellants. ${ }^{1}$ It is also known as a versatile, widely used polymer with numerous civil applications, such as an additive in paints and lacquer coatings for automobile and wood furniture. ${ }^{2,3}$ Recently, it has been applied in the fabrication of specific biosensors, especially in protein microarrays of biochips for its neutral effect on proteins and immobilization of enzymes. ${ }^{4-7}$ Nevertheless, most of the terrorist attacks occurring worldwide involve the misuse of $\mathrm{NC}$ and other explosives. Further, the preparation of paints and lacquer coatings may cause environmental contamination such as water pollution. Therefore, in order to eliminate the occurrence of terrorist attacks and decrease the pollution of water, it is necessary to find valid methods to detect NC.

Many methods have been reported for the detection of NC. Gas chromatography (GC) combined with electron ionization (EI) and mass spectrometry (MS) was adopted by Chajistamatiou and Bakeas to identify NC in bulk explosives. ${ }^{8}$ However, the

School of Chemical Engineering, Nanjing University of Science and Technology, Nanjing 210094, China. E-mail: xiaozhg@njust.edu.cn application of this method is hindered by the voluminous expensive instruments. MacMillan and co-workers used ion chromatography to determine NC in soil. ${ }^{9}$ They described the removal of impurities, extraction, hydrolysis and neutralization, followed by the analysis of free nitrate and nitrite through ion chromatography. Obviously, the disadvantage of this method is that it is laborious and time-consuming.

Considering the limitations of the above methods, it is necessary to enhance and improve NC detection technology, and more importantly, to develop a simple, highly-selective and widespread detection technology. ${ }^{\mathbf{1 0}}$

As a highly selective and highly sensitive detection method for a particular analyte, molecularly imprinted technology $(\mathrm{MIT})^{\mathbf{1 1 , 1 2}}$ has received increasing attention in recent years. Numerous papers in relation to MIT have been published, which involve extensive applied fields including biomedicine, ${ }^{\mathbf{1 3 - 1 6}}$ environmental protection, separation of substances ${ }^{\mathbf{1 7}}$ and so on. In general, the synthesis of a molecular imprinting polymer (MIP) ${ }^{18-21}$ involves the polymerization of a functional monomer in the presence of a cross-linking agent and template molecules. ${ }^{22}$ After the polymerization, the template molecules are removed from the polymer. As a result, the recognition sites, that are complementary to the template molecules in function and shape, ${ }^{23,24}$ are left in the polymer, which gives the MIP its 
ability to combine with a particular template molecule or its analogues efficiently and selectively. ${ }^{25}$

In spite of the synthesis of various imprinted materials, their commercial applications have not been put into practice yet. This results from the fact that the three-dimensional cavities in the synthesized MIP are not easily accessible to template molecules, thus leading to a poor binding capacity, slow binding kinetics and difficult template removal. To improve the traditional MIT, alternative approaches have been explored such as surface molecular imprinting, ${ }^{26,27}$ magnetic molecular imprinting, ${ }^{28,29}$ core-shell polymerization ${ }^{30}$ etc. Surface molecularly imprinted technology (SMIT) has been applied extensively, because the generated cavities are located on the surface of the materials, which decreases the resistance to mass transfer thus facilitating the contact of the template molecules with recognition sites in the polymer matrix. As a result, SMIT overcomes the disadvantages of the traditional MIT.

In this paper, through a simple, time-saving and facile in situ polymerization process, a surface imprinting polymer was synthesized to selectively detect $\mathrm{NC}$, while silica $\left(\mathrm{SiO}_{2}\right)$ was utilized as a core material. Inspired by the literature, ${ }^{31} 3$-(trimethoxysilyl) propylmethacrylate (MPS) was used in the form of a modifier to functionalize $\mathrm{SiO}_{2}$ powders with an acrylyl group. Thus through hydrogen bond interactions, it was easier for $\mathrm{SiO}_{2}$ powders to combine with NC molecules. Then the effects of the polymerization temperature and proportions of functional monomer and cross-linking agent on the adsorption capacity of $\mathrm{NC}$ were investigated. The surface imprinting polymer based on $\mathrm{SiO}_{2}\left(\mathrm{SiO}_{2} / \mathrm{MIP}\right)$ and surface non-imprinting polymer $\left(\mathrm{SiO}_{2} / \mathrm{NIP}\right)$ were characterized by scanning electron microscopy (SEM), Fourier transform infrared spectroscopy (FT-IR), thermogravimetric analysis (TGA) and X-ray diffraction (XRD). By contrasting $\mathrm{SiO}_{2} / \mathrm{NIP}$ and a traditional molecular imprinting polymer (TMIP), the adsorption capacity of the prepared $\mathrm{SiO}_{2} / \mathrm{MIP}$ was studied through ultraviolet-visible (UV-vis) spectrophotometry. Selectivity studies were conducted through attaching the $\mathrm{SiO}_{2} /$ MIP to NC and related structural analogues. The results showed that, $\mathrm{SiO}_{2} / \mathrm{MIP}$ could be applied practically to the highly selective and sensitive determination of NC in security checks and environmental protection.

\section{Results and discussion}

\subsection{Preparation and detection principle of $\mathrm{SiO}_{2} / \mathrm{MIP}$}

Fig. 1 illustrates the preparation process for poly(methylacrylic acid) (PMAA)/inorganic particle hybrid composites with highly selective properties for NC. Allowing for the scarce hydroxy groups on the surface of the purchased $\mathrm{SiO}_{2}$, the core material $\mathrm{SiO}_{2}$ was prepared directly based on the hydrolyzation of tetraethoxysilicane (TEOS), and silicon-hydroxyl condensation in a solution of ethanol and deionized water with ammonium hydroxide as a catalyst. In order to improve the interface properties, the silane coupling agent MPS was used to increase the surface activity of $\mathrm{SiO}_{2}$ and more importantly to functionalize the $\mathrm{SiO}_{2}$ particles with acrylyl groups for the follow-up experiments. Through ultrasonic dispersion of $\mathrm{MPS}^{-\mathrm{SiO}_{2}}$ and $\mathrm{NC}$ in the presence of methylacrylic acid (MAA) and ethylene glycol dimethacrylate (EGDMA), hydrogen bonds were formed between the ester group in MPS-SiO${ }_{2}$ and the hydroxy group in NC. At the same time, NC was orientated in the mixture by the formation of hydrogen bonds between its nitro group and the carboxy group in MAA. After the addition of 2,2-azobisisobutyronitrile (AIBN), a simple in situ polymerization took place by which NC was assembled and immobilized in the polymer network formed by MAA and EGDMA on the surface of the $\mathrm{SiO}_{2}$ particles. Subsequently, a mixture of methanol and acetic acid was used for the removal of the template NC, owing to the stronger hydrogen bonding interactions formed among carboxy groups in acetic acid, hydroxy groups in methanol and NC, in conditions of excess methanol and acetic acid. The NC was distributed on the surface of the $\mathrm{SiO}_{2}$ owing to its precombination with $\mathrm{MPS}-\mathrm{SiO}_{2}$, thus benefitting the final removal approach using methanol and acetic acid. After the removal of the template NC, cavities were left on the surface of $\mathrm{SiO}_{2}$, which retained the shape, size and functional groups of $\mathrm{NC}$, thus the resultant $\mathrm{SiO}_{2} / \mathrm{MIP}$ was able to selectively identify the template NC.

TMIP was prepared without the addition of $\mathrm{SiO}_{2}$; hydrogen bonds existed only between the hydroxy groups and nitro groups in NC and carboxy groups in MAA. In consequence, the template $\mathrm{NC}$ was stuck in the three-dimensional polymer networks formed after the polymerization process. When methanol and acetic acid were used to try to remove the template NC, access to the chasmal template NC was restricted which resulted in template residue in the polymer. As a result, the adsorption capacity of TMIP was poor in the rebinding test.

\subsection{FT-IR analysis}

Fig. 2 shows the FT-IR spectra of the prepared surface imprinting polymer based on $\mathrm{SiO}_{2}$ particles. Fig. 2(A) shows the FT-IR measurements of (a) $\mathrm{SiO}_{2}$ and (b) $\mathrm{MPS}^{-\mathrm{SiO}_{2}}$. The characteristic absorption peaks at $3372 \mathrm{~cm}^{-1}$ and $946 \mathrm{~cm}^{-1}$ belong to the stretching vibration and bending vibration of $\mathrm{Si}-\mathrm{OH}$ groups on the surface of $\mathrm{SiO}_{2}{ }^{32}$ The peaks located at $1047 \mathrm{~cm}^{-1}$ and $793 \mathrm{~cm}^{-1}$ are assigned to Si-O-Si stretching vibrations. The peaks observed at $2920 \mathrm{~cm}^{-1}$ and $1700 \mathrm{~cm}^{-1}$ belong to the stretching vibration of $-\mathrm{CH}_{3}$ and $\mathrm{C}=\mathrm{O}$ in MPS, which indicates that the $\mathrm{SiO}_{2}$ particles were successfully modified by MPS through a condensation reaction between hydroxy groups on the surface of $\mathrm{SiO}_{2}$ particles and methoxy groups in MPS.

Fig. 2(B) shows the FT-IR spectra of $\mathrm{SiO}_{2} / \mathrm{MIP}, \mathrm{SiO}_{2} / \mathrm{NIP}$ and NC. From the spectra, it can be seen that the characteristic peaks of $\mathrm{SiO}_{2} / \mathrm{MIP}$ and $\mathrm{SiO}_{2} / \mathrm{NIP}$ are highly consistent. The peak at $1723 \mathrm{~cm}^{-1}$ belongs to the stretching vibration of $\mathrm{C}=\mathrm{O}$ in MAA and EGDMA. Peaks at $1458 \mathrm{~cm}^{-1}, 1388 \mathrm{~cm}^{-1}$ and $1141 \mathrm{~cm}^{-1}$ are assigned to the bending vibrations of $\mathrm{C}-\mathrm{H}$ in $-\mathrm{CH}_{3}$ and $-\mathrm{CH}_{2}$. Peaks at $1253 \mathrm{~cm}^{-1}$ and $950 \mathrm{~cm}^{-1}$ are attributed to the $\mathrm{C}-\mathrm{O}$ stretching vibration and $-\mathrm{OH}$ in-plane rocking vibration in the carboxy group, respectively. In the spectrum of $\mathrm{NC}$, the strong absorption peaks located at $1637 \mathrm{~cm}^{-1}$ and $1274 \mathrm{~cm}^{-1}$ are assigned to the $-\mathrm{NO}_{2}$ stretching vibration, whereas peaks at $820 \mathrm{~cm}^{-1}, 747 \mathrm{~cm}^{-1}$ and $677 \mathrm{~cm}^{-1}$ belong to the $-\mathrm{NO}_{2}$ bending vibration. 

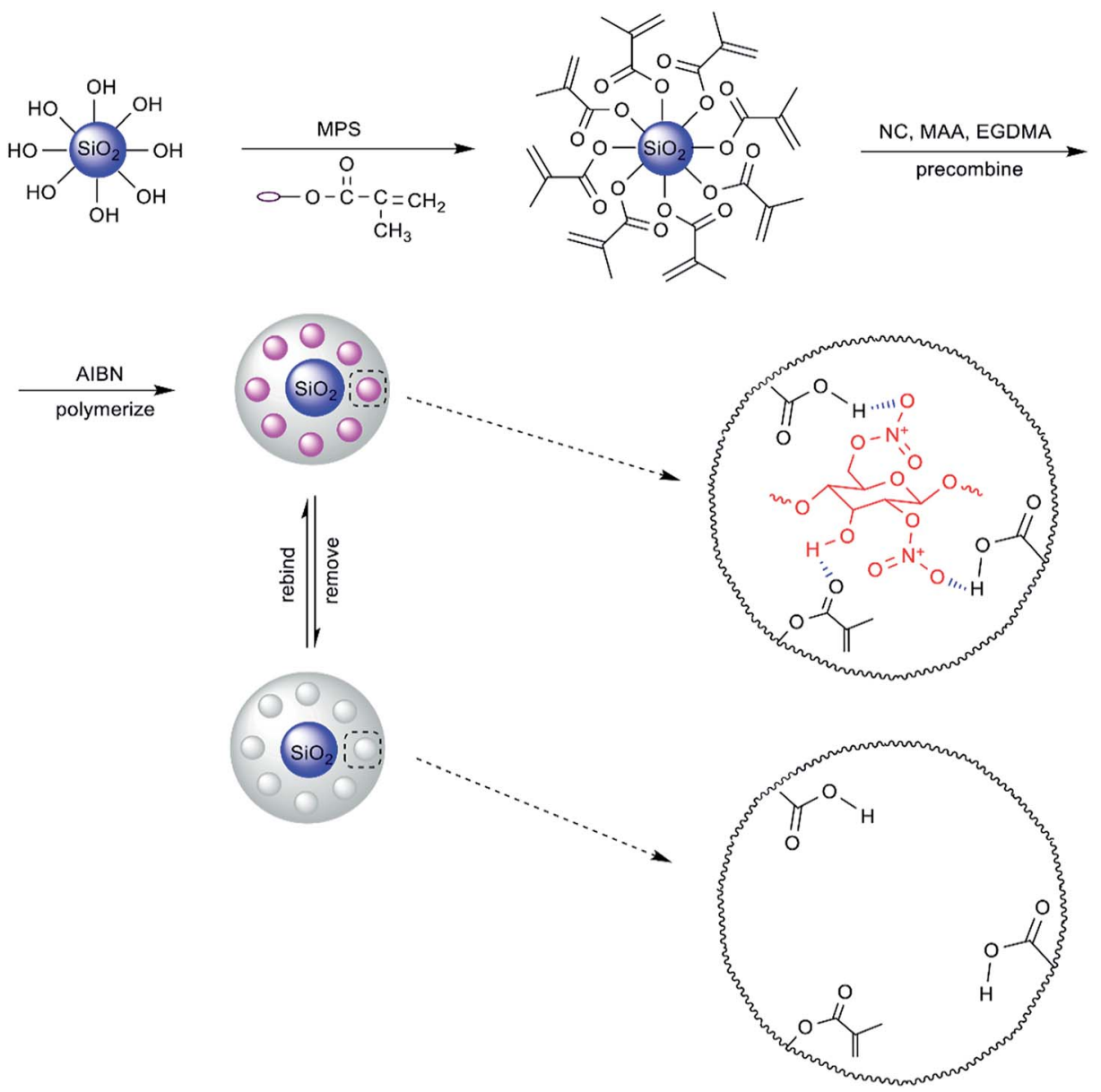

Fig. 1 Schematic diagram of the imprinting process of nitrocellulose on the surface of $\mathrm{SiO}_{2}$.

By contrasting the spectrum of $\mathrm{NC}$, it is clear that there are no remarkable absorption peaks of NC observed in the spectrum of $\mathrm{SiO}_{2} / \mathrm{MIP}$, which indicates the thorough removal of the template $\mathrm{NC}$ in the process of $\mathrm{SiO}_{2} / \mathrm{MIP}$ synthesis. This is because the imprinting sites in the cavities in $\mathrm{SiO}_{2} / \mathrm{MIP}$ are located on the surface of the $\mathrm{SiO}_{2}$ particles, leading to easier access to the NC for the mixture of methanol and acetic acid. On the other hand, the imprinting sites in TMIP are embedded into the threedimensional polymer network, which results in the difficulty for methanol and acetic acid to bind the NC molecules.

\subsection{Morphological analysis}

The morphologies of the synthesized $\mathrm{SiO}_{2}$ were studied by SEM as presented in Fig. 3. From Fig. 3(a) and (b), the synthesized $\mathrm{SiO}_{2}$ particles exhibit a spherical shape and smooth surface, while the diameter of the $\mathrm{SiO}_{2}$ particles ranges from $280 \mathrm{~nm}$ to $585 \mathrm{~nm}$. It is easy to see that the $\mathrm{SiO}_{2}$ particles are stacked and agglomerated together. This behavior might be due to the high surface free energy of $\mathrm{SiO}_{2}$ particles of small granularity. ${ }^{33}$

Fig. 4 depicts the SEM images of TMIP ( $a$ and b), TNIP ( $c$ and d), $\mathrm{SiO}_{2} / \mathrm{MIP}$ (e and $\mathrm{f}$ ) and $\mathrm{SiO}_{2} / \mathrm{NIP}$ ( $\mathrm{g}$ and $\mathrm{h}$ ). As shown in Fig. 4(a), the polymers in the traditional MIT sample exhibit cross-linked networks in which many cavities are observed, while TNIP is observed to form many large agglomerates. With higher magnification, the TMIP is shown to be made up of irregular spherules with many interstices (Fig. 4(b)), while the surface of TNIP is close-grained and fluctuant (Fig. 4(d)). A polyporous polymer matrix is observed in Fig. 4(e); $\mathrm{SiO}_{2}$ particles appear embedded in the polymer, and some $\mathrm{SiO}_{2}$ particles are on the surface of the polymer (Fig. 4(f)). In Fig. 4(g), many independent blocks are dispersed, and $\mathrm{SiO}_{2}$ particles are submerged into the polymer or on the surface of the polymer (Fig. 4(h)). The SEM images of embedded $\mathrm{SiO}_{2}$ particles in Fig. 4 indicate that the molecular imprinting process of $\mathrm{SiO}_{2} / \mathrm{MIP}$ takes place on the surface of the $\mathrm{SiO}_{2}$ particles. At the same time, some $\mathrm{SiO}_{2}$ particles are not embedded in the polymer, which might due to the easy agglomeration of $\mathrm{SiO}_{2}$ particles with small granularity. The carbonyl groups and hydroxyl on the surface of MPS-SiO $\mathrm{S}_{2}$ are occupied by other $\mathrm{SiO}_{2}$ particles in the process of agglomeration. As a result, this proportion of the $\mathrm{SiO}_{2}$ particles cannot contact the groups in MAA and EGDMA sufficiently. Thus in the polymerization process, it is difficult for agglomerated $\mathrm{SiO}_{2}$ particles to be embedded in the polymer.

With the reported imprinting process using template NC in the synthesis of MIP, the imprinted sites complementary with NC are left in the MIP once the template is removed, leading to the polyporous structures of TMIP and $\mathrm{SiO}_{2}$ /MIP. On the other hand, without the NC imprinting, there are no cavities and imprinted 

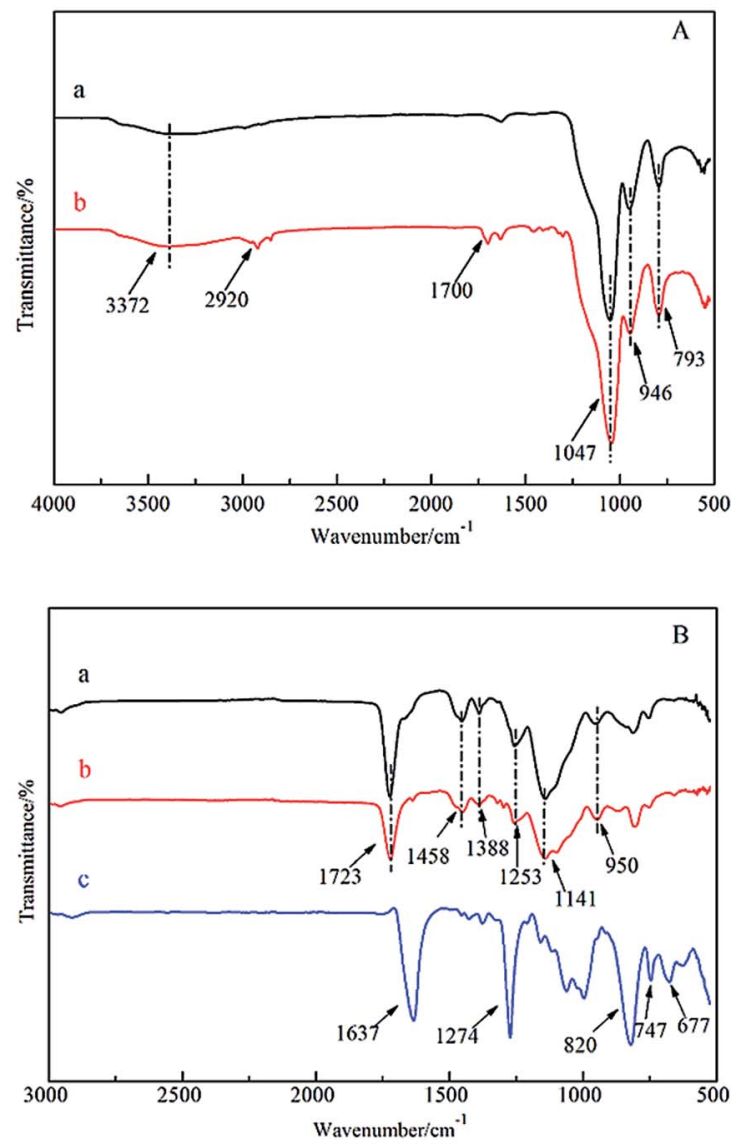

Fig. 2 FT-IR spectra of the prepared surface imprinting polymers based on silica particles: (A) (a) $\mathrm{SiO}_{2}$, (b) $M P S-\mathrm{SiO}_{2}$, and (B) (a) $\mathrm{SiO}_{2} / \mathrm{MIP}$, (b) $\mathrm{SiO}_{2} / \mathrm{NIP}$, (c) NC.

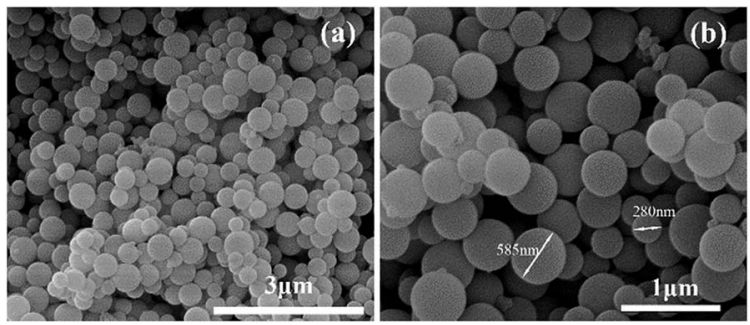

Fig. $3 \mathrm{SEM}$ images of the synthesized $\mathrm{SiO}_{2}$ particles: magnification (a) $20000 x$, (b) $40000 x$.

sites in TNIP and $\mathrm{SiO}_{2} / \mathrm{NIP}$, which explains the agglomerates and blocks observed in the SEM images of TNIP and $\mathrm{SiO}_{2} / \mathrm{NIP}$.

\subsection{XRD characterization}

Fig. 5 shows the X-ray diffractograms of TMIP, TNIP, $\mathrm{SiO}_{2} / \mathrm{MIP}$, $\mathrm{SiO}_{2} / \mathrm{NIP}$ and $\mathrm{SiO}_{2}$. In the X-ray diffractogram of $\mathrm{SiO}_{2}$ particles, the wide hump in the range of $15^{\circ}$ to $30^{\circ}$ is typical for amorphous silica. ${ }^{34}$ The $\mathrm{SiO}_{2} / \mathrm{MIP}$ does not have diffraction peaks, while peaks in $\mathrm{SiO}_{2} / \mathrm{NIP}$, TMIP and TNIP can be seen at an angle of $15^{\circ}$. Meanwhile, the intensity of the peaks decreases progressively according to the sequence of TNIP $>\mathrm{SiO}_{2} / \mathrm{NIP}>$
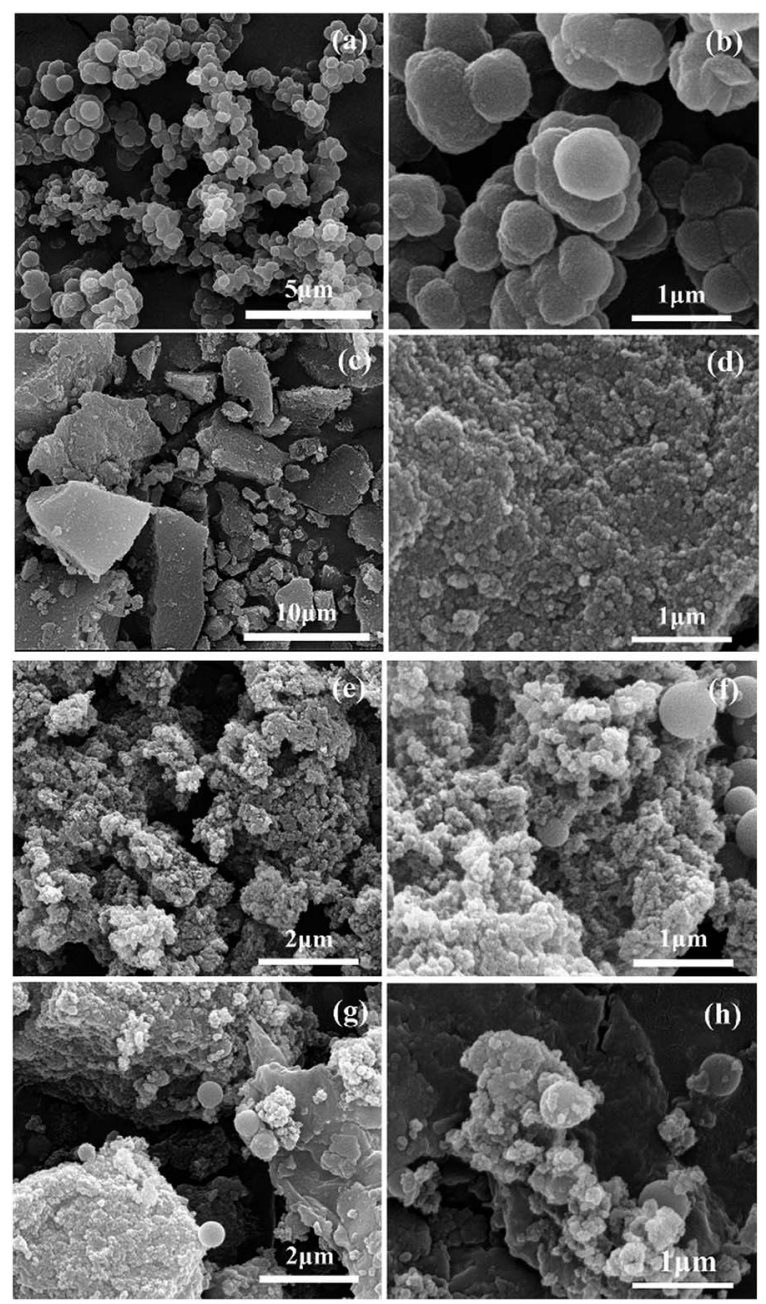

(h)

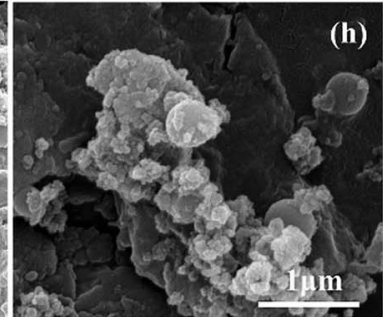

Fig. 4 SEM images of TMIP ( $a$ and b), TNIP ( $c$ and d), SiO $/$ MIP (e and f), $\mathrm{SiO}_{2} / \mathrm{NIP}$ (g and h). Magnification (a) $10000 \times,(b, d, f$ and h) 40000×, (c) $5000 \times$, (e and g) 20000 $\times$

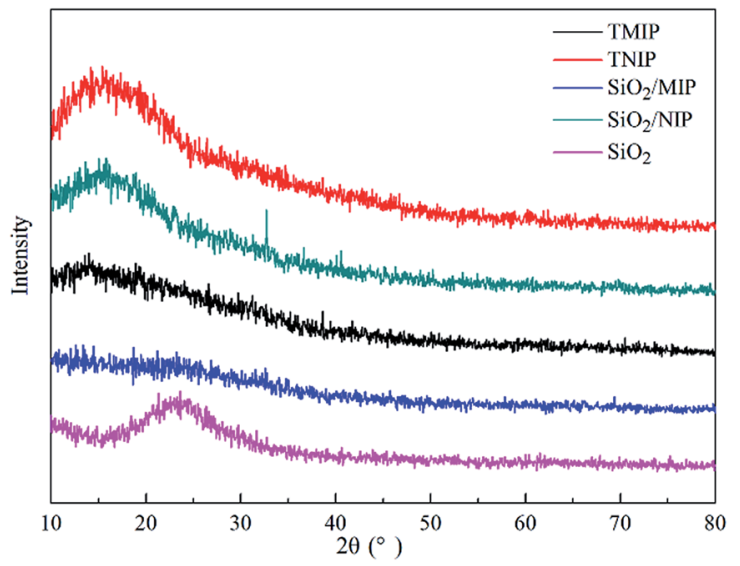

Fig. 5 X-ray diffractograms of TMIP, TNIP, SiO $/ \mathrm{MIP}_{2} \mathrm{SiO}_{2} / \mathrm{NIP}$ and $\mathrm{SiO}_{2}$.

TMIP. It can be concluded that the crystallinity of NIP is higher than that of MIP, and with imprinted sites on the surface of $\mathrm{SiO}_{2}, \mathrm{SiO}_{2} / \mathrm{MIP}$ is more amorphous than TMIP. 
The results suggest that the amorphous states of MIP could result from imprinting by NC. In other words, compared with pure PMAA, the imprinting process decreases the regularity of the crystalline region in order to make the template molecule orient in the polymer networks. When the polymers are imprinted with $\mathrm{SiO}_{2}$ as the core material, the amorphous degree of the polymers is at its maximum. This is due to the fact that the polymerization process is severely disorganized when affected by the hydrogen bond interactions among $\mathrm{MPS}-\mathrm{SiO}_{2}$, MAA and NC, which makes the polymerization process deviate greatly from the regular pathway of chain growth of a crystalline polymer, thus leading to the formation of amorphous polymers.

\subsection{Thermal properties}

The TGA curves of TMIP, TNIP, $\mathrm{SiO}_{2} / \mathrm{MIP}$ and $\mathrm{SiO}_{2} / \mathrm{NIP}$ in Fig. 6 show scans from $50{ }^{\circ} \mathrm{C}$ to $600{ }^{\circ} \mathrm{C}$ in an atmosphere of nitrogen. The thermal degradation process of TMIP and $\mathrm{SiO}_{2} / \mathrm{MIP}$ consists of four stages. The weight loss of TMIP and $\mathrm{SiO}_{2} / \mathrm{MIP}$ at $200{ }^{\circ} \mathrm{C}$ is less than $4 \%$, but it increases steeply between $200{ }^{\circ} \mathrm{C}$ and $270{ }^{\circ} \mathrm{C}$. This is followed by a sluggish rise from $270{ }^{\circ} \mathrm{C}$ to $457^{\circ} \mathrm{C}$ and then the curves reach a plateau. In contrast, TNIP and $\mathrm{SiO}_{2} / \mathrm{NIP}$ go through three stages with the increase of temperature: TNIP and $\mathrm{SiO}_{2} / \mathrm{NIP}$ have a weight loss of nearly $6 \%$ at $200{ }^{\circ} \mathrm{C}$ and show a straightforward increase in weight loss from $330{ }^{\circ} \mathrm{C}$ with a final constant weight at $457^{\circ} \mathrm{C}$.

The $4 \%$ weight loss of $\mathrm{SiO}_{2} / \mathrm{MIP}$ (and TMIP) and $6 \%$ weight loss of $\mathrm{SiO}_{2} / \mathrm{NIP}$ (and TNIP) at $200{ }^{\circ} \mathrm{C}$ result from adsorbed water. The $50 \%$ weight loss of $\mathrm{SiO}_{2} / \mathrm{MIP}$ (56\% for TMIP) from $200{ }^{\circ} \mathrm{C}$ to $270{ }^{\circ} \mathrm{C}$ is attributed to the formation of six-membered cyclic intramolecular anhydrides. ${ }^{35}$ The sluggish $30 \%$ weight loss of $\mathrm{SiO}_{2} / \mathrm{MIP}$ (36\% for TMIP) from $270{ }^{\circ} \mathrm{C}$ to $457^{\circ} \mathrm{C}$ derives from degradation to $\mathrm{CO}_{2}$ and $\mathrm{H}_{2} \mathrm{O}$. The weight loss of $\mathrm{SiO}_{2} / \mathrm{NIP}$ (TNIP) from $330{ }^{\circ} \mathrm{C}$ is due to the degradation of PMAA.

The residual weights of TMIP, TNIP, $\mathrm{SiO}_{2} / \mathrm{MIP}$ and $\mathrm{SiO}_{2} / \mathrm{NIP}$ are presented in Table 1.

The results show that $\mathrm{SiO}_{2} / \mathrm{NIP}$ (TNIP) is more stable than $\mathrm{SiO}_{2} / \mathrm{MIP}$ (TMIP), and that $\mathrm{SiO}_{2} / \mathrm{MIP}$ is more stable than TMIP in the same way. This is consistent with the morphology

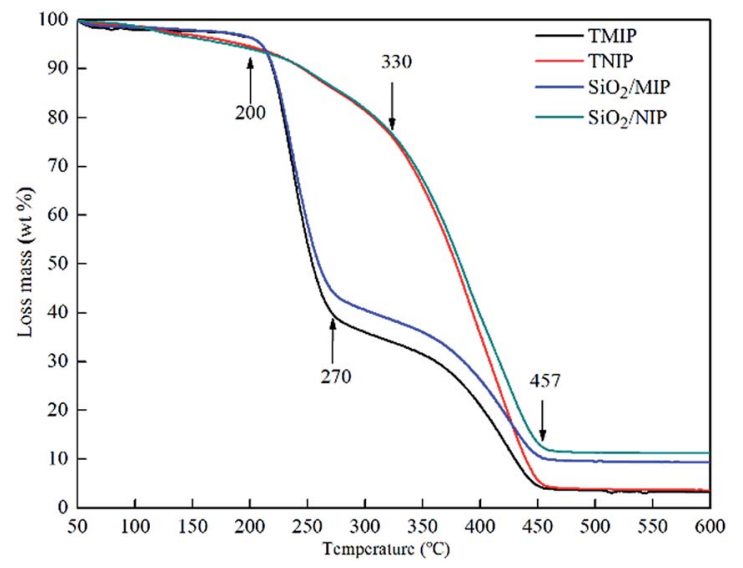

Fig. 6 TGA traces showing the thermal decomposition of TMIP, TNIP, $\mathrm{SiO}_{2} / \mathrm{MIP}$ and $\mathrm{SiO}_{2} / \mathrm{NIP}$ in a nitrogen atmosphere.
Table 1 The residual weights of the prepared four polymers from their TGA curves

\begin{tabular}{lc}
\hline Polymer & $\begin{array}{l}\text { Residual weight } \\
(\%)\end{array}$ \\
\hline TMIP & 3.8 \\
TNIP & 4.1 \\
$\mathrm{SiO}_{2} /$ MIP & 9.7 \\
$\mathrm{SiO}_{2} /$ NIP & 11.5 \\
\hline
\end{tabular}

observations of the traditional and surface imprinting polymers. $\mathrm{SiO}_{2} / \mathrm{NIP}$ is made up of many bulk agglomerates, therefore, it is more difficult for $\mathrm{SiO}_{2} / \mathrm{NIP}$ to transfer the heat when the external temperature is rising, compared with the polyporous polymer networks of $\mathrm{SiO}_{2} / \mathrm{MIP}$, which have lower resistance to heat transmission. It ultimately depends on whether the polymers are imprinted by a template molecule or not. At the same time, $\mathrm{SiO}_{2} /$ MIP is more stable than TMIP, which confirms the successful imprinting on the surface of $\mathrm{SiO}_{2}$ by $\mathrm{NC}$, and explains the excellent stability of $\mathrm{SiO}_{2}$ in the trial range of $50-600{ }^{\circ} \mathrm{C}$.

\subsection{Adsorption capacity}

It is essential to study the adsorption capacity of $\mathrm{SiO}_{2} / \mathrm{MIP}$ and $\mathrm{SiO}_{2} / \mathrm{NIP}$ for the template NC; this is a critical parameter which can reflect the ability of a material to detect a particular substance. To assess whether surface molecular imprinting technology leads to an excellent adsorption capacity for the template molecule, TMIP and TNIP were compared with $\mathrm{SiO}_{2} /$ MIP and $\mathrm{SiO}_{2} / \mathrm{NIP}$. Fig. 7 explicitly presents the adsorption capacities ( $Q$ values) of $\mathrm{SiO}_{2} / \mathrm{MIP}, \mathrm{SiO}_{2} / \mathrm{NIP}$, TMIP and TNIP for NC. From the adsorption graph (Fig. 7), it is clear that the $Q$ value of $\mathrm{SiO}_{2} / \mathrm{MIP}$ is far above (approximately 21 times) that of $\mathrm{SiO}_{2} / \mathrm{NIP}$. Furthermore, the $Q$ value of TMIP is lower than that of $\mathrm{SiO}_{2} / \mathrm{MIP}$. The $Q$ value of $\mathrm{SiO}_{2} / \mathrm{MIP}$ is about 3.5 times the $Q$ value of TMIP. The results show that $\mathrm{SiO}_{2} / \mathrm{MIP}$ has an excellent adsorption performance for NC, with a maximum adsorption amount of $1.7 \mathrm{mg} \mathrm{mg}^{-1}$ when the concentration of $\mathrm{NC}$ is $2 \mathrm{mg} \mathrm{ml}^{-1}$, and through the surface imprinting process, the adsorption capacity is improved effectively.

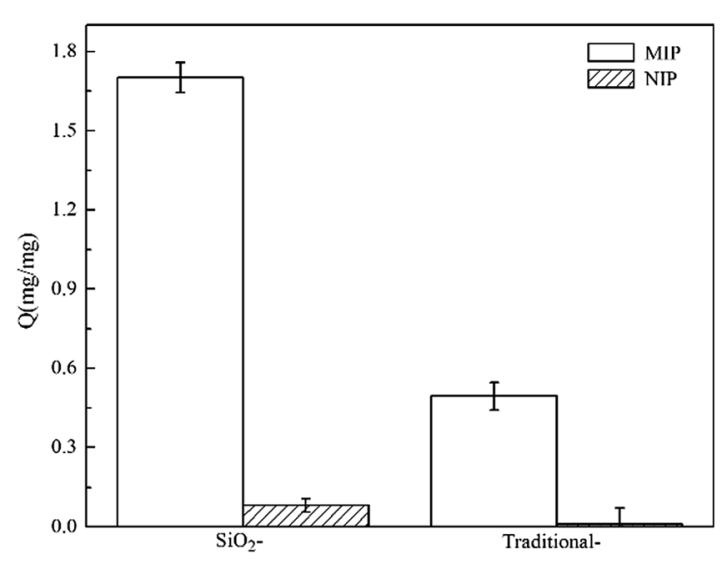

Fig. 7 Adsorption graph of $\mathrm{SiO}_{2} / \mathrm{MIP}, \mathrm{SiO}_{2} / \mathrm{NIP}, \mathrm{TMIP}$ and TNIP 


\subsection{Optimization of the polymerization conditions}

In order to identify appropriate conditions for the synthesis of $\mathrm{SiO}_{2} / \mathrm{MIP}$, the temperature and the proportions of functional monomer and cross-linking agent were studied in this paper. The component proportions and different temperature conditions used in this work are given in Table 2. The adsorption capacities of $\mathrm{SiO}_{2} / \mathrm{MIP}$ and $\mathrm{SiO}_{2} / \mathrm{NIP}$ prepared using the different polymerization temperatures and proportions are displayed in Fig. 8.

The polymerization temperature is important for the formation of a polymer network. With a lower external temperature, the polymerization process is difficult to initiate. However, when the temperature is too high, the polymerization advances very quickly, even developing into an implosion. The proportions of the functional monomer and cross-linking agent are another important parameter. A lower amount of crosslinking agent is beneficial for increasing the cross-linking index of the final polymers and speeding up the process of polymerization. However, excessive cross-linking agent can result in the formation of a rigid polymer, which is detrimental to the adsorption capacity for NC.

In consideration of the explosion hazard of $\mathrm{NC}$ at higher temperatures and the reactive ability of MAA at low temperatures, the temperatures of $45{ }^{\circ} \mathrm{C}, 50{ }^{\circ} \mathrm{C}$ and $55{ }^{\circ} \mathrm{C}$ were chosen for polymerization. As shown in Fig. 8(A), when the polymerization temperature was controlled at $45{ }^{\circ} \mathrm{C}$, the resulting $\mathrm{SiO}_{2} /$ MIP realized the best adsorption performance. With a temperature of $45{ }^{\circ} \mathrm{C}$, the $Q$ value of $\mathrm{SiO}_{2} / \mathrm{MIP}$ was 20.9 times that of $\mathrm{SiO}_{2} / \mathrm{NIP}, 1.2$ times that of $\mathrm{SiO}_{2} / \mathrm{MIP}$ prepared at $50{ }^{\circ} \mathrm{C}$, and 3.7 times that of $\mathrm{SiO}_{2} / \mathrm{MIP}$ prepared at $55{ }^{\circ} \mathrm{C}$. This indicates that the polymerization is exactly initiated at the temperature of $45^{\circ} \mathrm{C}$. The decomposition of the initiator is an endothermal reaction, and the decomposition rate of AIBN is slow. When the temperature is increased, more free radicals can be produced by AIBN. Plenty of free radicals attack the monomers and accelerate the process of chain propagation. Chain propagation is an exothermic process. So at higher temperatures, the reaction balance deviates to the depolymerization processes, which results in the formation of a polymer with a low polymerization degree. The polymer networks of $\mathrm{SiO}_{2} / \mathrm{MIP}$ with a low polymerization degree are loose and cannot immobilize NC molecules sufficiently. However, the $\mathrm{SiO}_{2} / \mathrm{MIP}$ prepared at $45^{\circ} \mathrm{C}$ has the appropriate cross-linking network density to fix more NC

Table 2 Effects of temperature and proportion on adsorption capacity to NC

\begin{tabular}{llllllll}
\hline & $\begin{array}{l}\text { NC } \\
\text { Variate }\end{array}$ & $\begin{array}{l}\text { MAA } \\
(\mathrm{g})\end{array}$ & $\begin{array}{l}\text { EGDMA }) \\
(\mathrm{mmol})\end{array}$ & $\begin{array}{l}\mathrm{MPS}^{2} \mathrm{SiO}_{2} \\
(\mathrm{~g})\end{array}$ & $\begin{array}{l}\text { AIBN } \\
(\mathrm{g})\end{array}$ & $\begin{array}{l}\text { Acetone } \\
(\mathrm{ml})\end{array}$ & $\begin{array}{l}\mathrm{T} \\
\left({ }^{\circ} \mathrm{C}\right)\end{array}$ \\
\hline $\mathrm{T}$ & 0.1 & 3 & 9 & 0.1 & 0.1642 & 30 & 45 \\
& & & & & & & 50 \\
& & & & & & & 55 \\
Proportion & 0.1 & 3 & 9 & 0.1 & 0.1642 & 30 & 50 \\
& & & 12 & & & & \\
& & & 15 & & & &
\end{tabular}
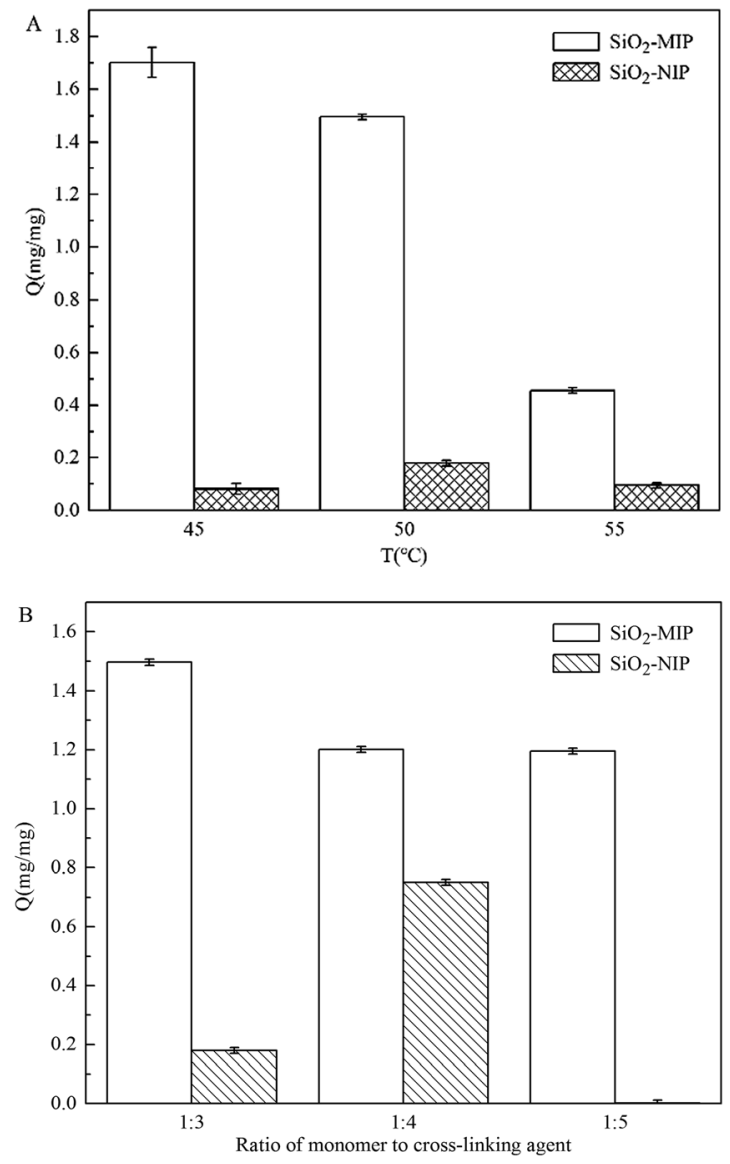

Fig. 8 Influence of polymerization temperature (A) and the ratio of monomer to cross-linker (B) for $\mathrm{SiO}_{2} / \mathrm{MIP}$ and $\mathrm{SiO}_{2} / \mathrm{NIP}$ on the adsorption of $\mathrm{NC}$.

molecules, and is not too rigid to hinder the access of NC to the imprinted sites during the recombination process. The results show that increasing the temperature is favorable for the polymerization process, but it is adverse to the adsorption of NC.

From the adsorption capacities graph of $\mathrm{SiO}_{2} / \mathrm{MIP}$ with different proportions of functional monomer and cross-linking agent (Fig. 8(B)), the $\mathrm{SiO}_{2} / \mathrm{MIP}$ prepared with the ratio of $1: 3$ has the best adsorption capacity and specificity, while with the ratio of $1: 4$, the specificity of $\mathrm{SiO}_{2} / \mathrm{MIP}$ is inferior. The adsorption capacity of $\mathrm{SiO}_{2} / \mathrm{MIP}$ for $\mathrm{NC}$ is 8.3 times and 857 times that of $\mathrm{SiO}_{2} / \mathrm{NIP}$, when prepared with ratios of $1: 3$ and $1: 5$, respectively, while the adsorption capacity of $\mathrm{SiO}_{2} / \mathrm{MIP}$ is 1.6 times that of $\mathrm{SiO}_{2} / \mathrm{NIP}$ when prepared with a ratio of $1: 4$. It is concluded that the maximum adsorption capacities can be reached when the temperature is $45{ }^{\circ} \mathrm{C}$ and the ratio of functional monomer to cross-linking agent is $1: 3$.

\subsection{Selectivity of $\mathrm{SiO}_{2} / \mathrm{MIP}$}

The structures of NC and its analogues are shown in Fig. 9. NC, and its analogues methyl cellulose (MC), carboxymethyl cellulose (CMC) and hydroxypropyl cellulose (HPC), are derivatives of cellulose, which are formed through substitution reactions of hydroxyl groups with nitric ester, methoxyl, carboxymethyl and 


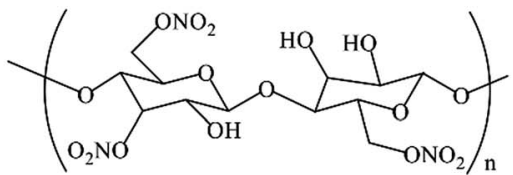

A<smiles>COCC(OC(O)C(O)C(O)C(O)COC(C)(C)C)C(O)COC(C)(C)C</smiles>

B

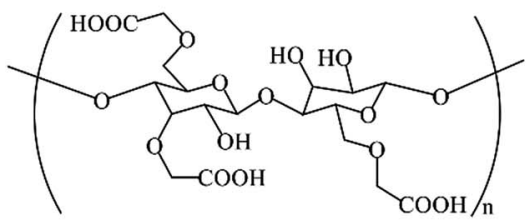

C

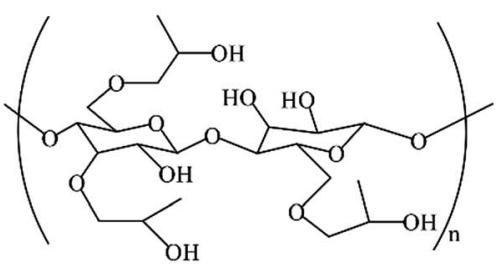

D

Fig. 9 Structures of NC (A) and its analogues: $M C(B), C M C(C)$ and HPC (D).

hydroxypropyl groups, respectively. The $\mathrm{SiO}_{2} / \mathrm{MIP}$ and $\mathrm{SiO}_{2} / \mathrm{NIP}$ were prepared with a polymerization temperature of $45^{\circ} \mathrm{C}$ and a ratio of monomer to cross-linking agent of $1: 3$. The adsorption capacities of $\mathrm{SiO}_{2} / \mathrm{MIP}$ and $\mathrm{SiO}_{2} / \mathrm{NIP}$ particles for the three analogues of NC in aqueous solutions are shown in Fig. 10. Meanwhile, the corresponding UV-vis spectra and standard curves are depicted in Fig. 11. In comparison with $\mathrm{SiO}_{2} / \mathrm{NIP}$, it is obvious that $\mathrm{SiO}_{2} / \mathrm{MIP}$ possesses higher adsorption capacities for the analogues of NC. This results from the fact that the

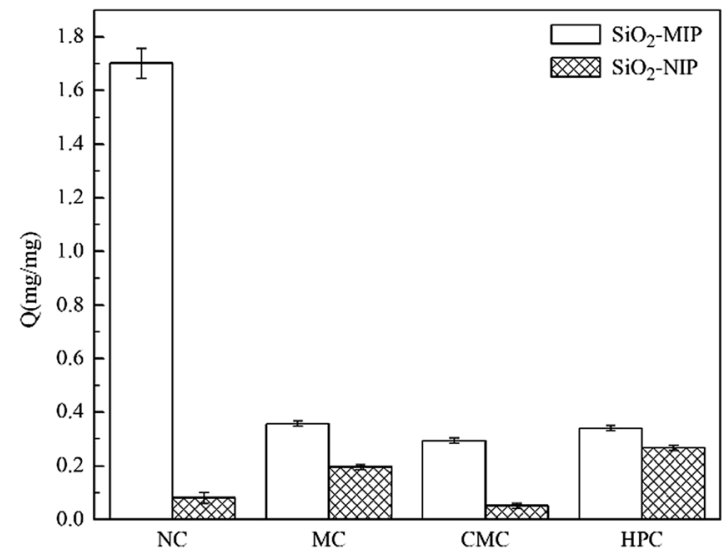

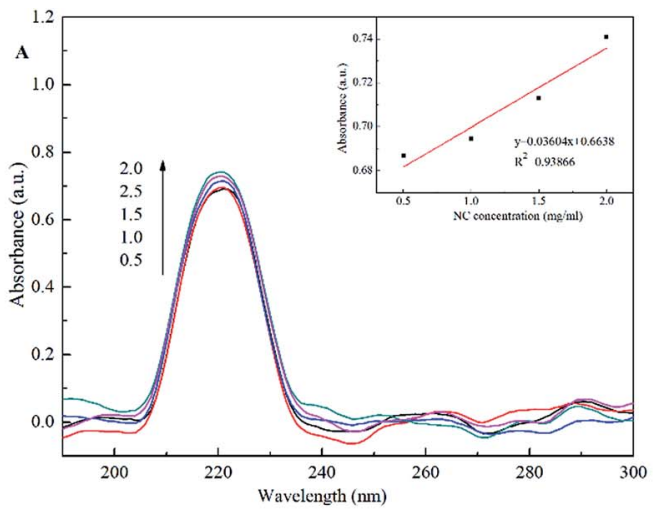
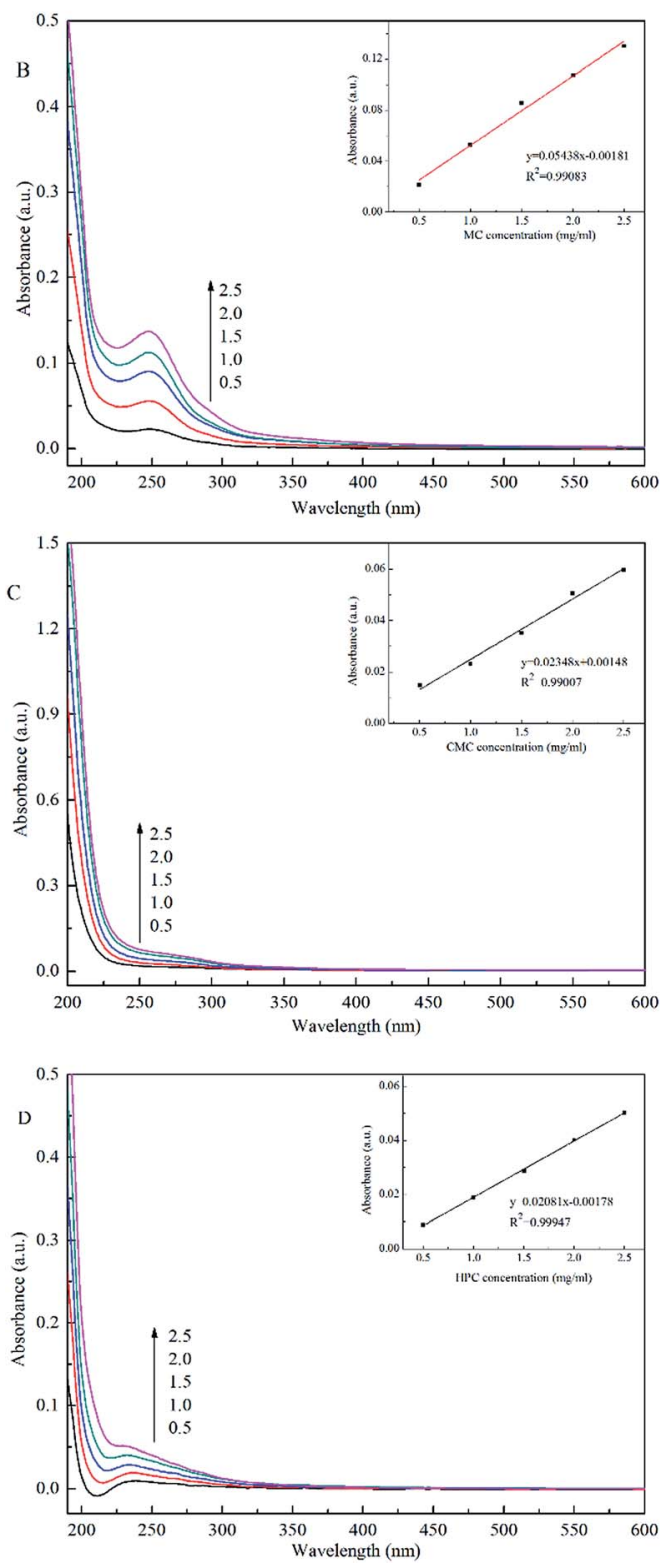

Fig. 11 UV-vis spectra of NC (A) and its analogues: MC (B), CMC (C), and HPC (D). The insets show the standard curves for each substance. The solvent for NC in this work was acetone; deionized water was used as the solvent for the other analogues, without any exception.

Fig. 10 Binding amounts of different cellulose derivatives. 
imprinting cavities and bigger surface area inside the $\mathrm{SiO}_{2} / \mathrm{MIP}$ make it easier for it to combine with analogues of NC, while no imprinting sites are available inside the $\mathrm{SiO}_{2} / \mathrm{NIP}$. However, the adsorption capacities of $\mathrm{SiO}_{2} / \mathrm{MIP}$ towards MC, CMC and HPC are very weak. The adsorption capacity of $\mathrm{SiO}_{2} / \mathrm{MIP}$ for NC is approaching 5 times more than that for $\mathrm{CMC}$, which can be ascribed to the unsuitable imprinting cavities inside $\mathrm{SiO}_{2} / \mathrm{MIP}$ for MC, CMC and HPC in terms of shape, size, and functional distribution. The results confirm the particular selectivity of $\mathrm{SiO}_{2} / \mathrm{MIP}$ for NC.

\section{Conclusions}

This paper introduces a novel detection method for NC using surface molecularly imprinted technology. The synthesized $\mathrm{SiO}_{2} /$ MIP consists of a polyporous and amorphous polymer matrix on the surface of $\mathrm{SiO}_{2}$ particles. Through FT-IR analysis, the removal of NC is shown to be thorough; there is no residual $\mathrm{NC}$ in imprinted materials. The thermal analysis and study of crystalline states confirm the successful imprinting of NC in the polymers. The prepared $\mathrm{SiO}_{2} / \mathrm{MIP}$ exhibits a high adsorption capacity and an excellent selectivity for NC, which opens a new pathway for the detection of NC. This method could also be applied to the detection of other flammable explosives. The $\mathrm{SiO}_{2} / \mathrm{MIP}$ material could be further used in security checks and contaminant adsorption.

\section{Experimental}

\subsection{Reagents and materials}

Nitrocellulose (NC, A grade) was provided by North Sichuan Nitrocellulose Co., China. 2,2-Azobisisobutyronitrile (AIBN, 98.5\%), 3-(trimethoxysilyl) propylmethacrylate (MPS, 97\%), ethanol (99.7\%), acetic acid (99.5\%) and deionized water were purchased from Nanjing Chemical Reagent Co., Nanjing, China. Methylacrylic acid (MAA, 98\%), tetraethoxysilicane (TEOS), acetone (99.7\%) and methanol (99.5\%) were obtained from Sinopharm Chemical Reagent Co., Nanjing, China. Ammonium hydroxide was provided by Shanghai Lingfeng Chemical Reagent Co., China. Ethylene glycol dimethacrylate (EGDMA, 98\%) was purchased from Aladdin Reagent Co., Shanghai, China. Methyl cellulose (MC, $15 \mathrm{mPa} \mathrm{s}$ ) was purchased from Meryer Chemical Technology Co., Shanghai, China. Carboxymethyl cellulose (CMC, 600-1000 mPa s, USP grade) and hydroxypropyl cellulose (HPC, M. W.100 000) were purchased from Macklin Biochemical Co., Shanghai, China. AIBN was recrystallized from ethanol before use, and all other chemicals were used directly without purification.

\subsection{Surface pre-treatment of $\mathrm{SiO}_{2}$ particles}

$\mathrm{SiO}_{2}$ particles were prepared according to the previously reported method. ${ }^{23}$ Then MPS was used to improve the affinity of the $\mathrm{SiO}_{2}$ particles for NC. Briefly, $\mathrm{SiO}_{2}$ particles $(0.5 \mathrm{~g})$, deionized water $(5 \mathrm{ml})$, aqueous ammonia $(6 \mathrm{ml})$, and MPS $(3 \mathrm{ml})$ were ultrasonically dispersed in ethanol $(50 \mathrm{ml})$ for $1 \mathrm{~h} .{ }^{36}$ Then the mixture was transferred into a $150 \mathrm{ml}$ round-bottom flask and stirred at $75{ }^{\circ} \mathrm{C}$ in a dry nitrogen atmosphere for $4 \mathrm{~h}$. After the reaction, the products were centrifuged and washed with ethanol three times to remove the unreacted MPS. Finally, the resultant $\mathrm{MPS}-\mathrm{SiO}_{2}$ particles were obtained after a vacuum drying procedure.

\subsection{Preparation of $\mathrm{SiO}_{2} / \mathrm{MIP}$}

$\mathrm{SiO}_{2} / \mathrm{MIP}$ particles were prepared through in situ polymerization in which MAA was used as a functional monomer and EGDMA was used as a cross-linking agent. Briefly, NC (0.1 g) was dissolved in acetone $(30 \mathrm{ml})$ and then MAA (3 mmol), EGDMA ( $9 \mathrm{mmol}$ ), and $\mathrm{MPS}-\mathrm{SiO}_{2}$ particles $(0.1 \mathrm{~g})$ were dispersed in the NC solution by ultrasonication for $10 \mathrm{~min}$. Subsequently, AIBN $(0.1642 \mathrm{~g})$ was added and the above solution was transferred to a $150 \mathrm{ml}$ round-bottom flask to react at $50{ }^{\circ} \mathrm{C}$ with continuous stirring in a dry nitrogen atmosphere for about $4 \mathrm{~h}$. Finally, the polymers were added to methanol/acetic acid $(4: 1, \mathrm{v} / \mathrm{v})$ solution with ultrasonication for $2 \mathrm{~h}$ to remove the NC. The resultant $\mathrm{SiO}_{2} / \mathrm{MIP}$ particles were obtained by vacuum drying after washing with ethanol and deionized water and centrifuging three times to remove residual methanol and acetic acid. As a control, the corresponding $\mathrm{SiO}_{2} / \mathrm{NIP}$ was synthesized using an identical method but without the addition of NC.

\subsection{Preparation of TMIP}

TMIP particles were synthesized for comparison; the preparation procedure was as follows: NC $(0.1 \mathrm{~g})$ was dissolved in acetone $(30 \mathrm{ml})$. MAA $(3 \mathrm{mmol})$ and EGDMA ( $9 \mathrm{mmol})$ were added to the solution above following ultrasonication for $10 \mathrm{~min}$. Subsequently, AIBN (0.1642 g) was added, the mixture was transferred to a $150 \mathrm{ml}$ round-bottom flask and the reaction was processed at $50{ }^{\circ} \mathrm{C}$ with continuous stirring in a dry nitrogen atmosphere for about $4 \mathrm{~h}$. After the final removal of NC and vacuum drying, the resultant TMIP particles were obtained.

The TNIP particles were synthesized using the same method but in the absence of the NC template.

\subsection{Adsorption capacities of $\mathrm{SiO}_{2} / \mathrm{MIP}$ and $\mathrm{SiO}_{2} / \mathrm{NIP}$}

Adsorption capacities were studied using the following procedures: $10 \mathrm{mg} \mathrm{SiO}_{2} / \mathrm{MIP}$ ( $\mathrm{SiO}_{2} / \mathrm{NIP}$, TMIP or TNIP) were added into a $10 \mathrm{ml} 2 \mathrm{mg} \mathrm{ml}^{-1} \mathrm{NC}$ solution. After ultrasonication for $2 \mathrm{~h}$, the supernatant liquid was collected through centrifugation. The concentration of supernatant liquid was measured by UV-vis spectrophotometry. The NC amount bound by $\mathrm{SiO}_{2} / \mathrm{MIP}$ was calculated by the following equation:

$$
Q=\left(c_{0}-c_{e}\right) V / m
$$

where, $Q\left(\mathrm{mg} \mathrm{mg}^{-1}\right)$ is the NC amount bound by $\mathrm{SiO}_{2} / \mathrm{MIP}\left(\mathrm{SiO}_{2} /\right.$ NIP, TMIP or TNIP), $c_{0}\left(\mathrm{mg} \mathrm{ml}^{-1}\right)$ is the initial concentration of $\mathrm{NC}, c_{e}\left(\mathrm{mg} \mathrm{ml}^{-1}\right)$ is the concentration of the supernatant liquid, $V(\mathrm{ml})$ is the volume of NC solution, $m(\mathrm{mg})$ is the mass of $\mathrm{SiO}_{2} /$ MIP ( $\mathrm{SiO}_{2} / \mathrm{NIP}$, TMIP or TNIP).

\subsection{Effects of polymerization conditions on adsorption capacity}

To evaluate the effects of polymerization temperature and the proportions of functional monomer and cross-linking agent on 
the adsorption capacity of $\mathrm{SiO}_{2} / \mathrm{MIP}$, the polymerization process was conducted at different temperatures and monomer to crosslinking ratios.

Temperature: NC (0.1 g) was dissolved in acetone $(30 \mathrm{ml})$ and then MAA ( $3 \mathrm{mmol}$ ), EGDMA ( $9 \mathrm{mmol}$ ), and $\mathrm{MPS}^{\mathrm{S}} \mathrm{SiO}_{2}$ particles $(0.1 \mathrm{~g})$ were dispersed in the NC solution by ultrasonication for $10 \mathrm{~min}$. Subsequently, AIBN (0.1642 g) was added, the mixture was transferred to a $150 \mathrm{ml}$ round-bottom flask and the reaction was processed at either $45^{\circ} \mathrm{C}$ or $55^{\circ} \mathrm{C}$ with continuous stirring in a dry nitrogen atmosphere for $4 \mathrm{~h}$. After the final removal of NC and vacuum drying, the resultant MIP particles were obtained. The amount of bound NC was calculated according to eqn (1).

Proportions: NC $(0.1 \mathrm{~g})$ was dissolved in acetone $(30 \mathrm{ml})$ and then MAA ( $3 \mathrm{mmol}$ ), EGDMA (12 mmol or $15 \mathrm{mmol}$ ), and MPS$\mathrm{SiO}_{2}$ particles $(0.1 \mathrm{~g})$ were dispersed in NC solution by ultrasonication for $10 \mathrm{~min}$. Subsequently, AIBN (0.1642 g) was added, the mixture was transferred to a $150 \mathrm{ml}$ round-bottom flask and the reaction was processed at $50{ }^{\circ} \mathrm{C}$ with continuous stirring in a dry nitrogen atmosphere for $4 \mathrm{~h}$. After the final removal of NC and vacuum drying, the resultant MIP particles were obtained. The amount of bound NC was calculated according to eqn (1).

\subsection{Selectivity performance of $\mathrm{SiO}_{2} / \mathrm{MIP}$ and $\mathrm{SiO}_{2} / \mathrm{NIP}$}

$20 \mathrm{mg}$ MC (CMC or HPC) were dissolved into $10 \mathrm{ml}$ deionized

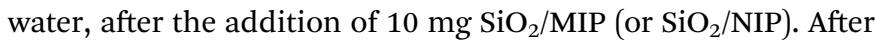
ultrasonication for $2 \mathrm{~h}$, the supernatant liquid was obtained by centrifugation. The concentration of MC (CMC or HPC) in the supernatant liquid was measured by UV-vis spectrophotometry. The amount of bound MC (CMC or HPC) was calculated according to eqn (1).

\subsection{Characterization}

The functional groups of pure $\mathrm{SiO}_{2}, \mathrm{MPS}^{-\mathrm{SiO}_{2}}, \mathrm{SiO}_{2} / \mathrm{MIP}, \mathrm{SiO}_{2} /$ NIP and NC were confirmed by Fourier transform infrared (FTIR, Nicolet iS10, America) spectroscopy in the range of 4000$500 \mathrm{~cm}^{-1}$. The morphological structures of $\mathrm{SiO}_{2} / \mathrm{MIP}$ particles were obtained from scanning electron microscopy (SEM, FEG250, Quanta, America, operating at $40 \mathrm{kV}$ ). The crystalline states of $\mathrm{SiO}_{2}$ and $\mathrm{SiO}_{2} / \mathrm{MIP}$ were determined through X-ray diffraction (XRD, D8 Advance, Germany) with conditions as follows: $\mathrm{Cu} \mathrm{K} \alpha$ radiation $(\lambda=1.5406), 40 \mathrm{kV}, 40 \mathrm{~mA}, 2 \theta$ scanning range of $10-90^{\circ}$, step size of $0.05^{\circ}$ and step time of $19.2 \mathrm{~s}$. The thermogravimetric analysis (TGA) was performed on a SDTQ600 thermal analyzer (PerkinElmer Pyris Diamond, America) under a nitrogen atmosphere at a heating rate of $10{ }^{\circ} \mathrm{C} \mathrm{min}^{-1}$. The adsorption capacity of $\mathrm{SiO}_{2} / \mathrm{MIP}$ particles was analyzed by ultraviolet-visible (UV-vis) spectrophotometry (Evolution 220, America).

\section{Conflicts of interest}

There are no conflicts to declare.

\section{Acknowledgements}

This work was supported by the Priority Academic Program Development of Jiangsu Higher Education Institutions (PAPD).

\section{References}

1 W. Tomaszewski, K. Cieślak and A. Zygmunt, Polym. Degrad. Stab., 2015, 111, 169-175.

2 X. Su, Q. Zhao, D. Zhang and W. Dong, Appl. Surf. Sci., 2015, 356, 610-614.

3 Z. Xiao, S. Ying, W. He, F. Xu and P. Sun, J. Appl. Polym. Sci., 2007, 105, 510-514.

4 L.-T. Yin, Y.-T. Lin, Y.-C. Leu and C.-Y. Hu, Sens. Actuators, B, 2010, 148, 207-213.

5 M. Cretich, V. Sedini, F. Damin, M. Pelliccia, L. Sola and M. Chiari, Anal. Biochem., 2010, 397, 84-88.

6 L. Hecht, D. van Rossum and A. Dietzel, Microelectron. Eng., 2016, 158, 52-58.

7 S. Ma, G. Song and N. Feng, Carbohydr. Polym., 2012, 89, 3640.

8 A. S. Chajistamatiou and E. B. Bakeas, Talanta, 2016, 151, 192-201.

9 D. K. MacMillan, C. R. Majerus, R. D. Laubscher and J. P. Shannon, Talanta, 2008, 74, 1026-1031.

10 H. Rao, M. Chen, H. Ge, Z. Lu, X. Liu, P. Zou, X. Wang, H. He, X. Zeng and Y. Wang, Biosens. Bioelectron., 2017, 87, 10291035.

11 M. Huang, T. Zhou, X. Wu and J. Mao, Chin. J. Chem. Eng., 2015, 23, 1698-1704.

12 Z. F. Cai, H. J. Dai, S. H. Si and F. L. Ren, Appl. Surf. Sci., 2008, 254, 4457-4461.

13 G. Erturk and B. Mattiasson, J. Chromatogr. B: Anal. Technol. Biomed. Life Sci., 2016, 1021, 30-44.

14 M. Perez, R. Concu, M. Ornelas, M. N. Cordeiro, M. Azenha and A. F. Silva, Spectrochim. Acta, Part A, 2016, 153, 661-668.

15 J. Li, S. M. Li and Z. G. He, Mater. Sci. Eng., C, 2017, 71, 9991003.

16 A. Sorribes-Soriano, F. A. Esteve-Turrillas, S. Armenta, M. de la Guardia and J. M. Herrero-Martinez, J. Chromatogr. A, 2017, 1481, 23-30.

17 Y. Zhang, J. Wan and X. Cao, Process Biochem., 2016, 51, 517527.

18 C. K. M. Faizal and T. Kobayashi, Polym. Eng. Sci., 2008, 48, 1085-1093.

19 B. R. Hart and K. J. Shea, Macromolecules, 2002, 35, 61926201.

20 D. Oliveira, C. P. Gomes, R. C. S. Dias and M. R. P. F. N. Costa, React. Funct. Polym., 2016, 107, 35-45.

21 C. Baggiani, C. Giovannoli, L. Anfossi, C. Passini, P. Baravalle and G. Giraudi, J. Am. Chem. Soc., 2012, 134, 1513-1518.

22 M. Torkashvand, M. B. Gholivand and G. Malekzadeh, Sens. Actuators, B, 2016, 231, 759-767.

23 R. Gao, J. Zhang, X. He, L. Chen and Y. Zhang, Anal. Bioanal. Chem., 2010, 398, 451-461. 
24 A. M. Shrivastav, S. P. Usha and B. D. Gupta, Biosens. Bioelectron., 2016, 79, 150-157.

25 W. Tan, Q. Yu, X. Ruan and X. Huang, Sens. Actuators, B, 2015, 212, 47-54.

26 H. Duan, X. Wang, Y. Wang, J. Li, Y. Sun and C. Luo, Sens. Actuators, B, 2016, 236, 44-51.

27 Y. Liu, B. Cao, P. Jia, J. An, C. Luo, L. Ma, J. Chang and K. Pan, J. Phys. Chem. A, 2015, 119, 6661-6667.

28 B. Yuan, X. Q. Yang, L. W. Xue, Y. N. Feng and J. H. Jiang, Bioresour. Technol., 2016, 222, 14-23.

29 H. Duan, X. Wang, Y. Wang, Y. Sun, J. Li and C. Luo, Anal. Chim. Acta, 2016, 918, 89-96.

30 Z. Wang and X. Cao, Process Biochem., 2015, 50, 1136-1145.
31 C. G. Xie, B. H. Liu, Z. Y. Wang, D. M. Gao, G. J. Guan and Z. P. Zhang, Anal. Chem., 2008, 80, 437-443.

32 N. Sun, X. Meng and Z. Xiao, Ceram. Int., 2015, 41, 1383013835.

33 Z. Xiao, P. Guo and N. Sun, J. Appl. Polym. Sci., 2017, 134, 44377.

34 N. Bogdanchikova, A. Pestryakov, M. H. Farias, J. A. Diaz, M. Avalos and J. Navarrete, Solid State Sci., 2008, 10, 908-914.

35 A. Asano and T. Kurotu, Polym. Degrad. Stab., 2002, 78, 137141.

36 X. Wang, J. Yu, Q. Kang, D. Shen, J. Li and L. Chen, Biosens. Bioelectron., 2016, 77, 624-630. 